\title{
TAVAKEELEST JA TAVAMATEMAATIKAST
}

\section{Leo Võhandu}

\author{
Ettekanne 24. mail 2005 Tartu Ülikooli pidulikul seminaril \\ "Mare Koit - 60"
}

Tänane seminar on tervenisti pühendatud Tartu Ülikooli raallingvistika professori Mare Koidu juubelile. Nii tähtsad juubelid algavad tavaliselt Laudatumiga, milles juubilari kaunid teod kõik halastamatult päevavalgele tuuakse. Meie seminaris nihkub Laudatum aga hoopis viimaseks sõnavõtuks, nii et ma pean esimese ettekandjana tahes-tahtmata korraga kahes rollis olema.

Lubage mul siis oma lugu sisse juhatada ühe südamest tuleva pöördumisega:

\section{Leo Võhandu $\rightarrow \boldsymbol{\bullet}$ ! Mare Koit}

Ma usun, et selle lause semantika on kõigile kohalviibijaile selge ilma mingi selgituseta. Lisan kohe etteruttavalt, et pöördumise üksikasjalikum klaarimine tuleb pärastpoole.

Et Mare tegudest õigesti aru saada ja neile vähegi väärikat hinnangut anda, peame uurima keele ja matemaatika vahekorda.

Keelel on oluline eelis matemaatika ees, sest kõik lapsed elavad keelekümbluses ja asuvad emapiimaga koos iseendale emakeele individuaalgrammatikat konstrueerima. Matemaatika osas peab laps paraku üpris pikka aega läbi ajama ühendsüsteemiga, s.o loendamisega. Tegelikult on see süsteem ideaalne ja täpne, aga pikavõitu.

Koolitee alguseks on laps loonud isikliku grammatika, oskab tavakeeles kõik asjad ära rääkida ja foneetiliselt enam-vähem õigesti ka kirjutada.

Mis edasi juhtub? Juhtub see, et koolis hakatakse emakeele metakeelt õpetama ja keskkooli lõpuks jõutakse seisu, mille kohta hiljuti manalasse varisenud tõsine keelemees Eduard Vääri ütles lühidalt: toodame poolkirjaoskamatuid.

Meenutame seejuures, et lapse keeleomandamise stardipositsioon ühiskonnas on igati hea. Tegemist on madalstardiga ema rinna najalt, mis garanteerib kiire lähte.

Matemaatika stardipositsioon on võrratult kehvem, sest kümblus puudub! Ühendsüsteem ei anna pärismatemaatikale nii vajalikku struktuurset mõtlemist. 
Kuidas asja parandada? Ma arvan, et eelkooliealistele sobiksid kümbluseks pedagoogilised kaardimängud (sic!). Näiteks Memory (Mälu), Lolli rõõm (Idiots delight) ja Plats puhtaks! (Sweep). (Ingliskeelsed nimed kergendavad infootsingut veebist.) Miks nii? Mängukaardid on abstraktsed objektid, mida saab loendada, järjestada, seostada (paari või tihisse panna) ja pealegi saab kaardihulga elementide vahel mitmeid erilisi kombinatsioone moodustada (koodid, motiivid jne). Neil mängudel on eesmärk, selged reeglid (kasvatuslikult tähtis) ja sportlik tulemus, milleta ükski mäng pole hea mäng. Eesti entsüklopeedia väitel peitub mängu motiiv küll vaid tegutsemisrõõmus ja mängul puudub eesmärk. Ärgem seda pedagoogide poolt välja öeldud mõtet siiski usume.

Mis koolis matemaatikast saab? Neli põhitehet võtavad aega viis aastat. Alles siis usaldatakse lapsi korrutama 3-4-kohalisi arve ja sedagi algoritmika seisukohast kõige viletsama algoritmi abil. (Aitaks näiteks Trachtenbergi meetod, mis vajab vaid topeldamist, poolitamist ja numbri 10-ni/9-ni täiendi võtmist.)

Kokkuvõtteks võib vist öelda, et ega matemaatika seis koolis eesti keele omast parem ole.

Ma loodan, et see lühiarutelu selgitas, kui rasketes tingimustes tuli Mare Koidul oma tööd alustada.

\section{Keel ja matemaatika}

Nihkume nüüd tavakeele ja -matemaatika tasemelt teaduse poole, Mare Koidu jahimaadele. Ma esitan teile kaks väidet, kaaluge endamisi, kas te olete nõus nendega või on tegemist mingi umbluuga.

Iga matemaatiline valem on interpreteeritav loomuliku keele lausena.

Iga loomuliku keele lause on väljendatav matemaatilise valemina.

Jätame nüüd igaühe enda arvamuse juurde ja märgime, et Marest ligi 90 aastat varem (1916) pani need väited kirja eesti talupoja järeltulijana sündinud ja 1891. a Tallinna Raudteekooli lõpetanud Jacob Linzbach. Ta pühendas kogu oma elu (1874-1953) nende väidete tõestamisele. J. Linzbach oli täielik iseõppija matemaatika ja keeleteaduse alal, ometi loevad praegu kõige kuulsamad semiootikud nagu U. Eco, J. Kristeva, kadunud J. Lotman jt teda semiootikas F. de Saussurega ühte ritta kuuluvaks. Praegu uurib J. Linzbachi pärandit innukalt TÜ professor A. Dulicenko.

J. Linzbachi esikteos "Printsipõ filosofskago jazõka. Opõt totsnago jazõkoznanija” (1916) pakub meie praegusele seltskonnale selle poolest erilist huvi, et see on tegelikult maailma esimene tõsine informaatikateaduslik üllitis. J. Linzbach pani oma 228-leheküljelise raamatu kirja sõttamineku hirmus.

Ta oli oma raallingvistilises mõtteviisis kogu muust maailmast tohutult ees. Ma toon paar näidet, kuidas J. Linzbachi tollane käsitlus seostub kaasajaga.

Liiasus. Me teame, et nii tavamatemaatikas kui tavakeeles on palju liiasust, millest meid päästab üleminek kahendsüsteemile. J. Linzbach näitas oma esikteoses, et kui ühendsüsteem on absoluutselt ideaalne ja täpne, siis kahendsüsteemil on piisav selgus maksimaalse lühidusega. 
Otseviide "Iga keele jaoks on kaks esitust - täielik ja kokkusurutud. Võime öelda, et iga täielik esitus peab olema ühendsüsteemis ja iga lühendesitus kahendsüsteemis.“ J. Linzbachil oli täielik arusaamine teksti liiasusest ja sellest lühendesitusega vabanemisest. "Mida rohkem te teksti kokku surute, seda rohkem aega kulub selle täpseks taastamiseks".

Matemaatikutele teadmiseks, et selles 1916. aasta raamatus on esitatud täielik neljatehteline kahendarvutusskeem. Huvitav oleks teada, kes mujal maailmas ja millal sellise skeemi esitas.

Kõnekas on kahendsüsteemile järgnev peatükk "Mõte ja intuitsioon kui arvusüsteemid“.

Paraku ta raamat (200 eksemplari) ja ka hilisem metakeele teooria "Transcendent algebra" (1921) hääbusid raamatukogude arhiividesse ammu enne kui tekkis küberneetika (Wiener 1948, Shannon 1948). Muide, J. Linzbachi 1921. aasta raamatut ei leidu üldse Eesti raamatukogudes ja arhiivides. Ilmselt on ainus koopia praegu minu käes. Sain selle Hollandist Utrechti ülikoolist.

Matemaatikuna ütleksin, et J. Linzbach lõi esimese kontseptialgebra. Kunstnikuna lõi ta piktograafilise metakeele, mille põhiidee on aga ääretult põnev. Ta tõi sisse tähistused diskreetse aja ja perioodiliste protsesside jaoks. Üpris huvitav on J. Linzbachi skeem asjade maailma ja hingelise maailma olekute ja tegevuste kirjeldamiseks. Muide, veel 1952. aastal ütles Moskva TA retsensent, et kui ta nägi J. Linzbachi käsikirjas sõna dušaa, siis ta enam edasi ei lugenudki. Meenutan, et küberneetikat hakati Nõukogude Liidus tunnistama alles alates 1956. aastast ja sedagi sõjaväeteadlaste otsesel nõudmisel.

Ma arvan, et kui loobuda J. Linzbachi piltkeelest ja mõisteid tähistada tavasõnadega, siis tekivad üsna lühikesed ja asjalikud väljendusskeemid. (Seda J. Linzbachi kontseptialgebrat arendame edasi oma ETF-i grandi 5918 abil. Puuetega inimesed vajavad suhteliselt lihtsat formaliseeritud keelt nii kirjas kui kõnes.)

Esitan siinkohal vaid mõned ilmsed metamärgid:

$+\quad$ ja, on, eksisteerib, koos

- $\quad$ ei, ei eksisteeri, puudub, on eraldatud, ilma, ..

$\mathrm{x} \quad$ korduv liitmine, tootmine, loomine

/ osa, kasutus, vajadus, kuuluvus

$\wedge>0$ tegutsejate koostöö, < $<$ kasutajate koostöö

$\sqrt{ } \quad$ millegi teke, sünd

$\infty \quad$ surm, millegi lõpp

\section{Jacob Linzbach ja Mare Koit}

Nüüd saame esimese eestlasest informaatiku J. Linzbachi metakeelt kasutada Eesti esimese raallingvistika professori Mare Koidu Laudatumi osaliseks maitseprooviks:

$\begin{array}{lll}\sqrt{ } \text { Mare } 1945 & & \text { Mare sündis } 1945 \\ \text { RaalLingv/ Mare } & \rightarrow & \text { Raallingvistika kuulub Marele (on osa Marest) } \\ \text { Keel ^(- Mare) } & \rightarrow & \text { Keel ei allu Marele } \\ \text { Keel^(1/ Mare) } \rightarrow & \text { Keel rahuldab Mare vajadusi }\end{array}$




$\begin{array}{lll}\operatorname{Keel}^{\wedge}(+ \text { Mare }) & \rightarrow & \text { Keel on Mare võimuses } \\ \text { Mare }^{\wedge} \text { mõistus } & \rightarrow & \text { Mare tegutseb mõistuse käsul }\end{array}$

\section{Riskid}

Mare pole üldse nii vagur inimene, kui ta pealt paistab. Ta riskib algusest peale tõsiselt. Ta esimene raamat (Koit 1983) enne lingvistikaga maadlema hakkamist oli õpetus sellest, kuidas käsitleda MUMPS-i (siiski mitte haigus, vaid dialoogiline andmebaas).

Nüüd ta tegeleb jälle dialoogi(de)ga. Ilmselt on see teema talle noorest peale jäänud südamelähedaseks. (Oli siiski nakkav!)

Dialoogis on peaaegu alati sees varjatud mõte. Metafoorid ja mõttevastandused... Tekstist on seda nähtamatute situatsioonimuutuste tõttu pagana raske püüda. Võtame kas või meie suure idanaabri keelest ühe lihtsa näite: zakuska ja jedaa. Kui dialoogis järsku hakatakse zakuska asemel jedaa'd pruukima. Mida see tähendab? Lihtsalt seda, et viin otsas ja peab otsustama, mida edasi teha...

Olgu nii! Lõpetan oma tõsise jutuarenduse sümpaatse daami Mare Koidu juubeliseminaril linzbachilikult:

Mõistus $\infty /$ Leo Leo mõistus on otsas

Leo - jutt $\quad$ Leo ilma lõppenud jututa

\section{Kirjandus}

Koit, Mare 1983. Programming in DIAMS-2 (textbook in Estonian). Tartu: University Press.

Linzbach, Jacob 1916. Printsipõ filosofskago jazõka. Opõt totšnago jazõkoznanija. Petrograd.

Linzbach, Jacob 1921. Transcendent Algebra. Reval, Estonia.

Shannon, Claude 1948. A Mathematical Theory of Communication. Bell System Technical Journal 27, 379-423, 623-656.

Wiener, Norbert 1948. Cybernetics. Control and Communication in the Animal and Machine. New York: Wiley.

Leo Võhandu (Tallinna Tehnikaülikool) on aktiivne informaatika, mänguteooria ja rakendusliku matemaatika propageerija. Ta on informaatikainstituudi eellase, endise infotöötluse kateedri rajajaid ja vastava eriala ellukutsujaid tehnikaülikoolis.

leov@staff.ttu.ee 